\title{
Image-guided stereotactic ablative radiotherapy for the liver: A safe and effective treatment
}

Citation for published version (APA):

Van De Voorde, L., Vanneste, B., Houben, R., Damen, P., van den Bogaard, J., Lammering, G., Dejong, K., de Vos-Geelen, J., Buijsen, J., Ollers, M., Berbee, M., \& Lambin, P. (2015). Image-guided stereotactic ablative radiotherapy for the liver: A safe and effective treatment. European Journal of Surgical Oncology, 41(2), 249-256. https://doi.org/10.1016/j.ejso.2014.10.053

Document status and date:

Published: 01/02/2015

DOI:

10.1016/j.ejso.2014.10.053

Document Version:

Publisher's PDF, also known as Version of record

Document license:

Taverne

Please check the document version of this publication:

- A submitted manuscript is the version of the article upon submission and before peer-review. There can be important differences between the submitted version and the official published version of record.

People interested in the research are advised to contact the author for the final version of the publication, or visit the DOI to the publisher's website.

- The final author version and the galley proof are versions of the publication after peer review.

- The final published version features the final layout of the paper including the volume, issue and page numbers.

Link to publication

\footnotetext{
General rights rights.

- You may freely distribute the URL identifying the publication in the public portal. please follow below link for the End User Agreement:

www.umlib.nl/taverne-license

Take down policy

If you believe that this document breaches copyright please contact us at:

repository@maastrichtuniversity.nl

providing details and we will investigate your claim.
}

Copyright and moral rights for the publications made accessible in the public portal are retained by the authors and/or other copyright owners and it is a condition of accessing publications that users recognise and abide by the legal requirements associated with these

- Users may download and print one copy of any publication from the public portal for the purpose of private study or research.

- You may not further distribute the material or use it for any profit-making activity or commercial gain

If the publication is distributed under the terms of Article $25 \mathrm{fa}$ of the Dutch Copyright Act, indicated by the "Taverne" license above, 


\title{
Image-guided stereotactic ablative radiotherapy for the liver: A safe and effective treatment
}

\author{
L. Van De Voorde ${ }^{\mathrm{a}, *}, \mathrm{~B}$. Vanneste ${ }^{\mathrm{a}}, \mathrm{R}$. Houben ${ }^{\mathrm{a}}$, P. Damen ${ }^{\mathrm{a}}$, \\ J. van den Bogaard ${ }^{\mathrm{a}}$, G. Lammering ${ }^{\mathrm{b}}$, K. Dejong ${ }^{\mathrm{c}}$, \\ J. de Vos-Geelen ${ }^{\mathrm{d}}$, J. Buijsen ${ }^{\mathrm{a}}$, M. Öllers ${ }^{\mathrm{a}}$, M. Berbée ${ }^{\mathrm{a}}$, P. Lambin ${ }^{\mathrm{a}}$ \\ ${ }^{a}$ Department of Radiation Oncology (MAASTRO), GROW School for Oncology and Developmental Biology, \\ Maastricht University Medical Centre +, Maastricht, The Netherlands \\ ${ }^{\mathrm{b}}$ Department of Radiation Oncology, Mediclin Robert Janker Klinik, Bonn, Germany \\ ${ }^{\mathrm{c}}$ Department of Surgery, Maastricht University Medical Centre +, Maastricht, The Netherlands \\ ${ }^{\mathrm{d}}$ Department of Internal Medicine, Medical Oncology Division, GROW School for Oncology and Developmental \\ Biology, Maastricht University Medical Centre +, Maastricht, The Netherlands
}

Accepted 23 October 2014

Available online 1 November 2014

\begin{abstract}
Aims: Stereotactic ablative body radiotherapy (SABR) is a non-invasive treatment option for inoperable patients or patients with irresectable liver tumors. Outcome and toxicity were evaluated retrospectively in this single-institution patient cohort.

Patients and methods: Between 2010 and 2014, 39 lesions were irradiated in 33 consecutive patients (18 male, 15 female, median age of 68 years). All the lesions were liver metastases $(n=34)$ or primary hepatocellular carcinomas $(n=5)$. The patients had undergone fourdimensional respiration-correlated PET-CT for treatment simulation to capture tumor motion. We analyzed local control with a focus on CT-based response at three months, one year and two years after treatment, looking at overall survival and the progression pattern.

Results: All patients were treated with hypofractionated image-guided stereotactic radiotherapy. The equivalent dose in 2 Gy fractions varied from 62.5 Gy to $150 \mathrm{~Gy}$, delivered in 3-10 fractions (median dose $93.8 \mathrm{~Gy}$, alpha/beta $=10$ ). The CT-based regression pattern three months after radiotherapy revealed partial regression in $72.7 \%$ of patients with a complete remission in $27.3 \%$ of the cases. The site of first progression was predominantly distant. One- and two-year overall survival rates were $85.4 \%$ and $68.8 \%$, respectively. No toxicity of grade 2 or higher according to the NCI Common Terminology Criteria for Adverse Events v4.0 was observed.

Conclusion: SABR is a safe and efficient treatment for selected inoperable patients or irresectable tumors of the liver. Future studies should combine SABR with systemic treatment acting in synergy with radiation, such as immunological interventions or hypoxic cell radiosensitizers to prevent distant relapse.
\end{abstract}

(C) 2014 Elsevier Ltd. All rights reserved.

Keywords: Stereotactic ablative body radiotherapy; Liver metastases; Hepatocellular carcinoma; Local control; Overall survival

\section{Introduction}

Hepatocellular carcinoma (HCC) and hepatic metastatic disease are significant clinical problems. ${ }^{1}$ With the introduction of new chemotherapeutic drugs, a paradigm shift in criteria for surgical resection and techniques like portal vein embolization and repeat resection, the five-year survival rates for patients with colorectal liver metastases

\footnotetext{
* Corresponding author. Tel.: +31 88445 5666; fax: +31 884455667 . E-mail address: Lien.vandevoorde@maastro.nl (L. Van De Voorde).
}

have doubled, from $30 \%$ to $60 \% .^{2-4}$ Unfortunately, the majority of patients with liver metastases are not surgical candidates because of tumor size, location, multifocality or inadequate hepatic reserve. For such patients, stereotactic ablative body radiotherapy (SABR) may be considered as an alternative treatment. ${ }^{5,6}$ SABR is a high-precision conformal external beam radiation that enables the delivery of large doses of radiation to tumors with reduced margins and steep dose gradients outside the target, thereby minimizing doses to surrounding normal tissues. It is the only 
truly non-invasive approach, combining high efficacy with minimal side effects in the oligometastatic situation. It has also emerged as a relatively new treatment for patients with HCC who are unfit for surgical resection or ablation. In addition, SABR is studied as a bridge to orthotopic liver transplantation for patients with HCC. HCC is known as a radiosensitive tumor and available data show a sustained tumor response with radiotherapy. ${ }^{7-9}$

In this study, we investigated a cohort of patients with HCC or oligometastatic liver tumors who were treated with SABR at the MAASTRO Clinic. This review was performed to report treatment response outcomes at three months, local control rate and progression pattern. In addition, we hypothesized that using four-dimensional positronemission-computed-tomography (4D-PET/CT)-based free breathing SABR on the liver with a higher radiotherapy dose would result in improved local control. ${ }^{9}$

\section{Patients and methods}

\section{Patient population}

After receiving institutional review board approval, we reviewed the records of 33 patients who had been treated at the MAASTRO Clinic with SABR for the liver. All the patients were required to have had a complete staging evaluation with history, physical exam, baseline liver function test and full-body imaging with positron emission tomography. Magnetic resonance imaging (MRI) or triple-phase contrast-enhanced computed tomography (CT) was performed to provide anatomical details of liver disease. We did not exclude patients with extrahepatic disease as long as it was amenable to other treatment (local or chemotherapy). Pathological confirmation of liver lesions prior to treatment was not required unless it was the first presentation of metastatic disease. The decision to treat patients with SABR was made by the multidisciplinary tumor board in the presence of at least one dedicated hepatobiliary surgeon.

\section{Radiotherapy technique}

Patients were immobilized in a supine position by the breast board bilateral arm support system and the knee and feet fixation system. The MAASTRO Clinic decided not to use liver fiducial implants to guarantee patient comfort and non-invasiveness. Because the liver continuously moves as the patient breathes, we used 4D-PET/CT for treatment planning. The advantage of the 4D-PET/CT technique is that patients can freely breathe during the radiation sessions. All patients received iodinated oral (Telebrix Gastro, $25 \mathrm{ml}$ ) and intravenous contrast (150 ml Xenetix 300, Guerbet, The Netherlands) for $15 \mathrm{~min}$ and $60 \mathrm{~s}$, respectively, before scanning. If available, magnetic resonance images were used for accurate tumor delineation. Delineation was done according to the current concepts of volume determination as outlined in the International Commission on Radiation Units and Measurements (ICRU) Report 83. Target definition was performed by contouring the gross tumor volume (GTV) based on contrast-enhanced CT and fluorodeoxyglucose (FDG) uptake. The GTV was considered to be identical to clinical target volume. Clinical target volume was consequently modified to create an internal target volume, accounting for tumor movement using the 4D-PET/CT image data. The planning target volume (PTV) was defined by adding a $1 \mathrm{~cm}$ isotropic margin for set-up inaccuracy and patient movement. Normal tissues including heart, esophagus, lungs, ribs, skin, spinal cord, stomach, small and large bowel, duodenum, kidneys and liver were defined as applicable.

Plans were designed using the Eclipse Treatment Planning System (Varian Medical Systems, Palo Alto, CA) and five to seven rotational intensity modulated beams or Volumetric Modulated Arc Therapy (VMAT/Rapidarc). A prescription isodose surface that covered $95 \%$ of the PTV was chosen (Fig. 1). The number of fractions and total radiotherapy dose were adapted to the risk of toxicity to the normal adjacent organs. When treated with a schedule of three fractions of $20 \mathrm{~Gy}$, the interval between two sessions should be more than $40 \mathrm{~h}$, but total treatment time was restricted to eight days. In a schedule of eight fractions of 7.5 Gy, radiotherapy was given every other day. When treated with 5 Gy per fraction, a patient can be irradiated on a daily basis. Before each treatment, a cone beam CT (CBCT) scan was made for accurate patient set-up. The CBCT was registered to the planning CT using an algorithm based on mutual information. For dosimetric accuracy, a complete three-dimensional (3D) cone beam dose verification procedure was performed (Fig. 2). ${ }^{10}$

\section{Follow-up and toxicity}

Follow-up consisted of imaging with either contrastenhanced spiral CT or contrast-enhanced dynamic MRI of the treated area. In addition, we evaluated clinical examination and liver function tests three months after completing SABR. Thereafter, we collected patient imaging studies at three-to six-month intervals. Tumor assessment was measured according to the modified Response Evaluation Criteria in Solid Tumors (RECIST) criteria version 1.1. ${ }^{11}$ Toxicity was scored using the NCI Common Terminology Criteria for Adverse Events (CTCAE) version 4.0. ${ }^{12}$ Any toxicity that occurred within three months after the start of SABR and that could theoretically be linked to the treatment was considered acute. After three months, toxicity was considered to be late. All patients were prescribed proton pump inhibitors to reduce the risk of luminal gastrointestinal toxicity until at least three months after the treatment.

\section{Statistics}

We performed an analysis with a follow-up update in July 2014. The main study endpoints were local control 


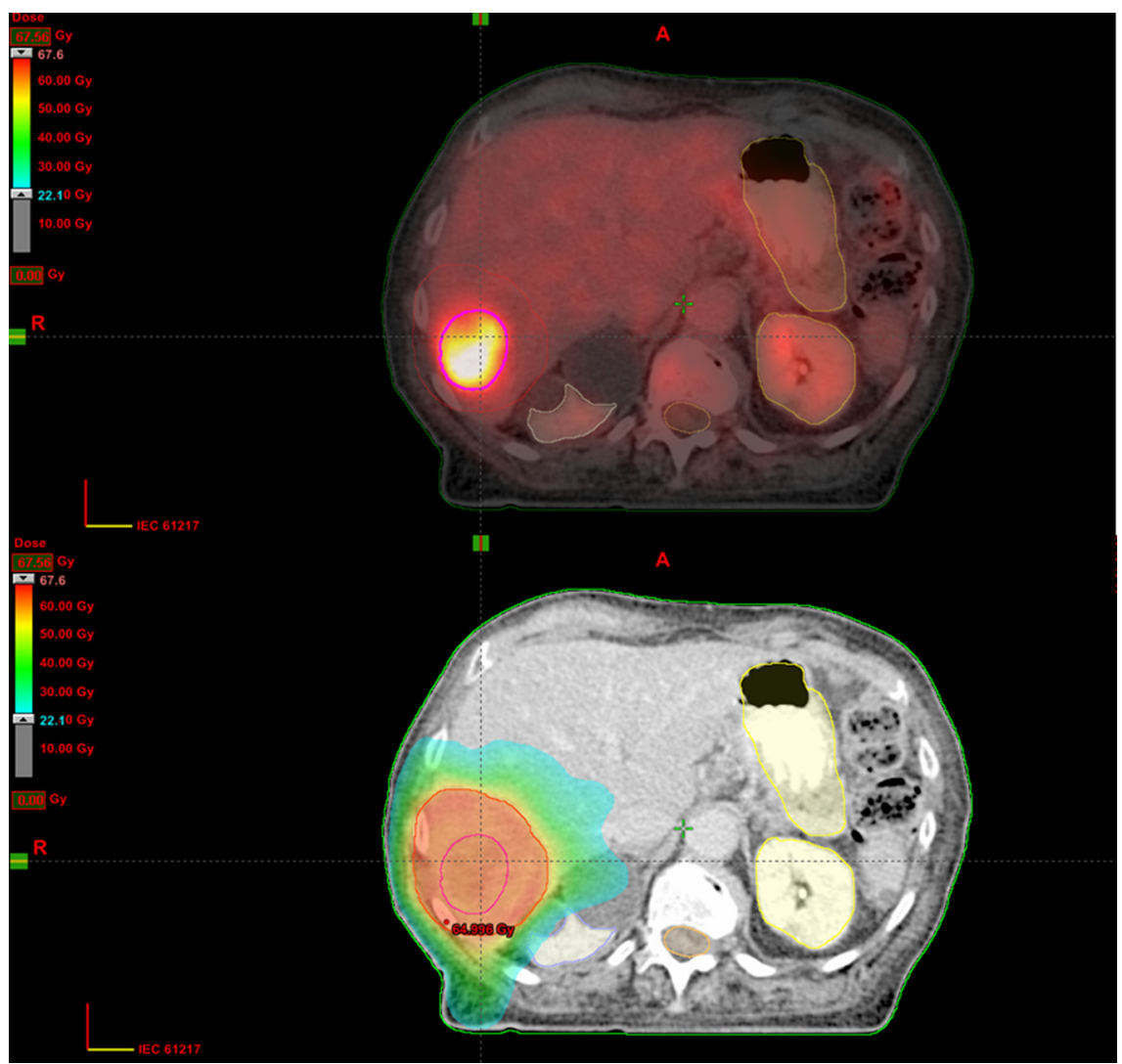

Figure 1. Respiratory-Correlated PET-CT with peroral and intravenous contrast used for tumor delineation (upper) and RapidArc treatment planning (lower).

and overall survival, estimated using methods developed by Kaplan and Meier. Survival curves were compared using the log-rank test. Local failure was defined per modified RECIST criteria for assessing tumor diameter and viable tumor tissue. Lesions that developed outside the liver were scored as distant progression. Comparison between subgroups was calculated with Pearson's chi-squared test. Survival and control times were calculated from the start of SABR. We hypothesized that local control is better when lesions are irradiated with higher radiotherapy doses.

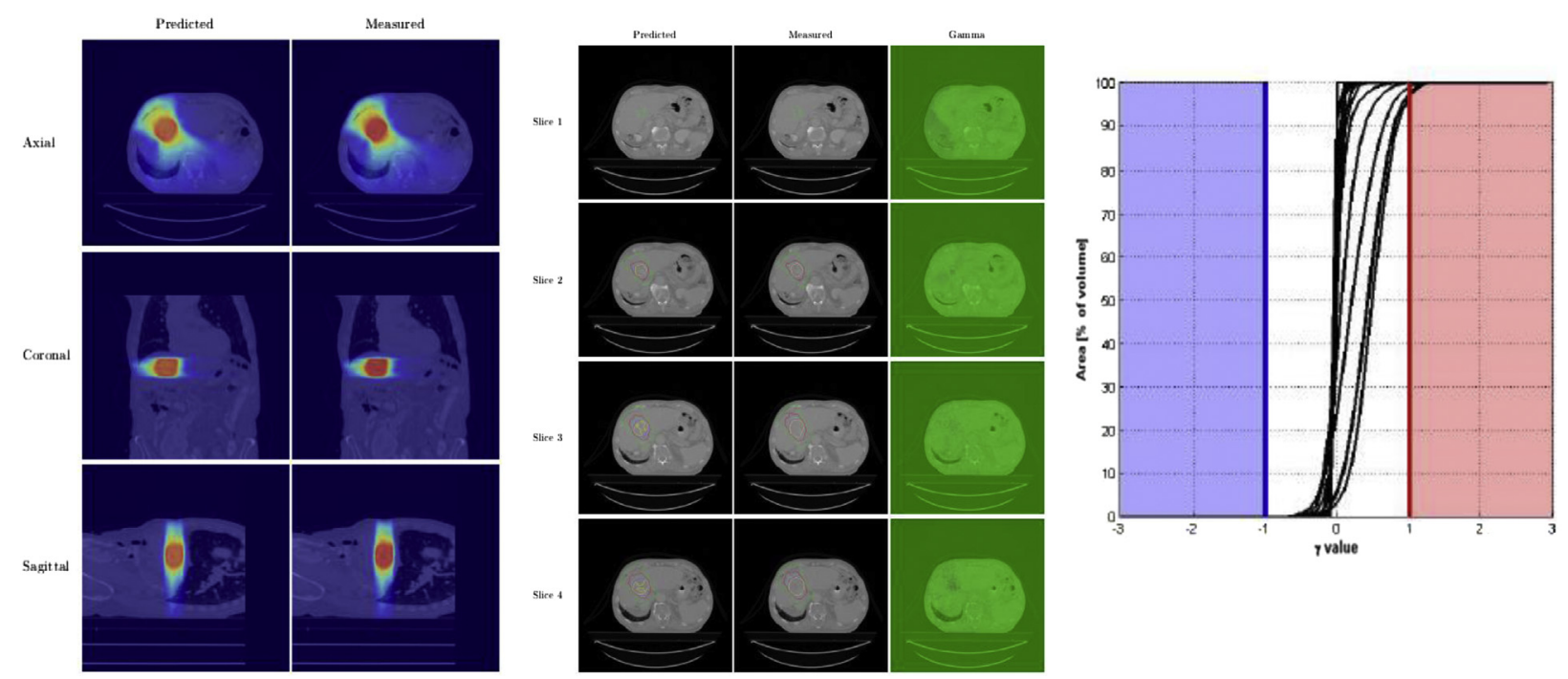

Figure 2. 3D in vivo dosimetry using megavoltage cone beam (left), gamma evaluation of the comparison between the planned and reconstructed dose distribution (middle) and gamma dose volume histogram (right). 
We tested this hypothesis with the Mann-Whitney $U$ test, comparing two dose groups based on a median split of equivalent dose in 2 Gy fractions (EQD2).

\section{Results}

\section{Patients}

From May 2010 to May 2014, 33 patients with 39 liver lesions were treated with SABR in the MAASTRO Clinic's Radiotherapy Department. Patient and tumor characteristics are listed in Table 1. Five patients had HCC with limited hepatic reserve, dictating a non-surgical approach. Twenty-eight patients had only one metastatic site, four patients were treated for two lesions and only one patient had three treated liver metastases. Table 1 shows that liver segment VIII was most often presented for stereotactic treatment given the proximity of the main intrahepatic

Table 1

Patient clinical data.

\begin{tabular}{ll}
\hline Characteristic & Value $(\%)$ \\
\hline Total number of patients & 33 \\
Total number of lesions & 39 \\
Age (years) & \\
$\bullet$ Mean & 68 \\
$\bullet$ Range & $46-81$ \\
Gender & \\
$\bullet$ Female & $15(45.5)$ \\
$\bullet$ Male & $18(54.5)$ \\
Number of lesions & \\
$\bullet 1$ & $28(84.8)$ \\
$\bullet 2$ & $4(12.1)$ \\
$\bullet 3$ & $1(3.0)$ \\
Primary tumor site & \\
$\bullet$ Colorectal & $17(51.5)$ \\
$\bullet$ Non-colorectal & $11(33.3)$ \\
$\bullet$ Hepatocellular & $5(15.2)$ \\
Involved liver segment & \\
$\bullet 2$ & $1(2.6)$ \\
$\bullet 3$ & $2(5.1)$ \\
$\bullet 4$ & $6(15.4)$ \\
$\bullet 6$ & $5(12.8)$ \\
$\bullet 7$ & $5(12.8)$ \\
$\bullet 8$ & $20(51.3)$ \\
Extrahepatic disease & \\
$\bullet$ No & $26(78.8)$ \\
$\bullet$ Yes & $7(21.2)$ \\
$\bullet$ Yes & \\
$\bullet$ No & $11(33.0)$ \\
EQD2 & $22(67.0)$ \\
$\bullet$ Below 100 Gy & $17(51.5)$ \\
$\bullet$ Equal or above 100 Gy & $16(48.5)$ \\
PTV volume (ml) & 22.9 \\
$\bullet$ Minimum & 758.3 \\
$\bullet$ Maximum & 170.1 \\
$\bullet$ Mean \\
Dosimetric value of the liver \\
$\bullet$ Mean dose (Gy) \\
$\bullet$ Mean volume healthy liver (ml) \\
\hline
\end{tabular}

vessels. Different fractionation schedules were used, depending on the location of the nearby organs at risk. If the tumor was located near the stomach or duodenal wall, we gave priority to the at-risk organs and increased the number of fractions. EQD2 varied from $62.5 \mathrm{~Gy}$ to 150 Gy delivered in 3-10 fractions (median dose $93.8 \mathrm{~Gy}$, alpha/beta $=10$ ). No patients were lost to follow-up and all the patients were evaluated for local control. One-third of patients $(n=11)$ received systemic therapy within six months before and/or after treatment with SABR. Thirty percent of patients $(n=10)$ had undergone liver surgery (hemihepatectomy or metastasectomy) in the past. Only one patient experienced multiple sessions of radiofrequency ablation to attempt to control his hepatocellular carcinoma.

\section{Treatment outcomes}

The CT-based regression pattern three months after radiotherapy revealed regression in $72.7 \%$ of patients with a complete remission in $27.3 \%$ of the cases (Fig. 3). The site of the first progression was predominantly distant. In $18.2 \%$ of patients, the progression pattern was distant only and in an equal percentage the pattern was distant and outfield hepatogenous. We found no progression at the treated site. About $42.4 \%$ of patients remained free from progression at the last follow-up (mean follow-up time was 21 months). For hepatocellular carcinoma, all five patients showed response on CT three months after SABR with $60 \%$ of them having partial response and $40 \%$ having a complete remission. Two of them (40\%) developed a new lesion in the liver suspect for hepatocellular carcinoma in the course of time. No patient with hepatocellular carcinoma developed in-field tumor relapse which can perhaps be explained by our high institutional treatment dose. Regarding patients with colorectal liver metastases, $24 \%$ patients $(n=4)$ were seen with complete remission, $41 \%$ patients with partial $(n=7)$ and $35 \%$ $(n=6)$ patients with stable disease. In the group of patients with non colorectal metastases $(n=11)$, the distribution of response was more of less the same with $27 \%$ complete response $(n=3), 45 \%$ partial response $(n=5)$ and three patients or $27 \%$ stable disease. There was no statistically significant difference in CT-based response between the different subgroups: colorectal, non colorectal metastases and hepatocellular carcinoma.

The one- and two-year overall survival rates were $85.4 \%$ and $68.8 \%$, for the whole group. The median survival was 29 months (Fig. 4). We report a median survival rate for patients with non colorectal metastases, colorectal metastases and hepatocellular carcinoma of 29,25 and 20 months respectively.

Regarding the dose-treatment effect, we recorded a significantly higher rate of complete remission with an $\mathrm{EQD} 2 \geq 100$ Gy ( $p$ value $=0.017$ ). The estimated median survival time for the high-dose radiotherapy group was 32 


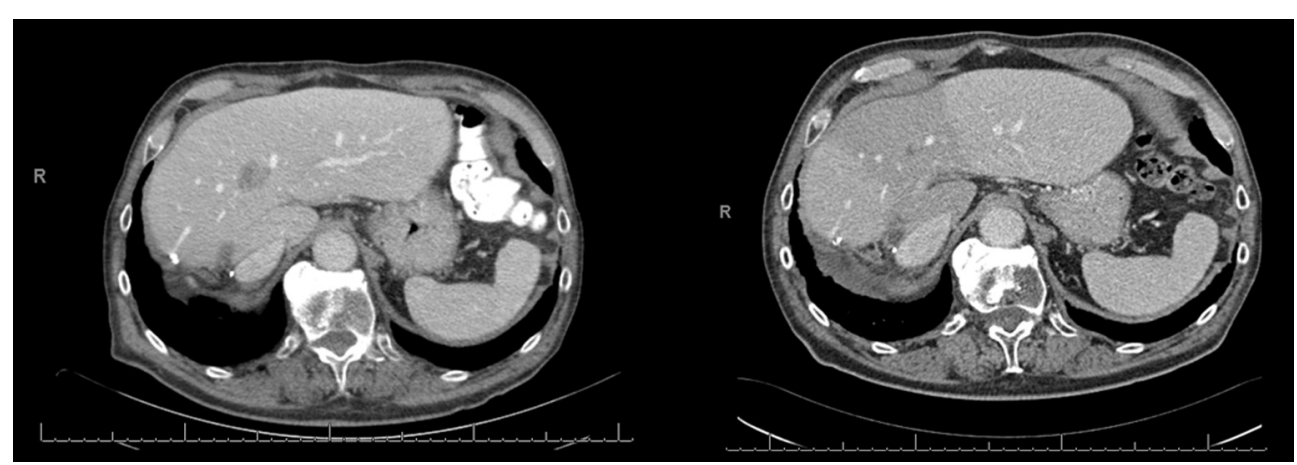

Figure 3. Four-phase liver CT-scan in a patient with a history of right hemihepatectomy presenting with a hypodense unsharp defined lesion in liver segment IVA (left). Portal venous phase imaging after SABR shows significant reduction of lesion diameter with perfusion defects associated with postradiotherapy effects (right).

months, compared with 25 months for the group that received a dose below $100 \mathrm{~Gy}$. Overall comparison of the difference in survival distribution between these two subgroups was not significant ( $p=0.109$; Fig. 4). Furthermore, PTV was significantly smaller for patients with complete or partial remission (average volume of 130 and $277 \mathrm{ml}$, respectively; $p=0.026$ ). Other than having a higher radiation dose and lesser volume of the irradiated target volume, we could identify no singular unifying characteristic for predicting the likelihood of SABR failure in the future.

\section{Treatment-related toxicity}

No patient experienced acute toxicity equal to or above grade 3 . When patients were asked about the side effects of treatment, the most commonly mentioned was fatigue $(n=11,33 \%)$. If needed we prescribed anti-emetics to use before treatment but only $24 \%$ of patients $(n=8)$ experienced grade 1 nausea. One patient who was treated with a high dose $(3 \times 20 \mathrm{~Gy})$ had a rise in temperature at the day of treatment and experienced flu-like symptoms after each session. Two patients presented with abdominal cramps and diarrhea, but these symptoms were self-limiting and did not require any medical intervention. Only one patient had skin toxicity with grade 1 itchy erythema; the patient had fully recovered three weeks after treatment. Regarding late toxicity, one patient developed a cough three months after SABR with radiographic consolidation of the right lung base. Corticosteroids were started based on a tentative diagnosis of radiation pneumonitis and the symptoms resolved over the course of one month. We found no radiationinduced liver disease (RILD). There was no marked difference in reported toxicity between patients with liver oligometastases and primary hepatocellular carcinoma. We notice that only one patient treated for hepatocellular carcinoma with SABR had underlying liver cirrhosis ChildPugh A.

\section{Discussion}

Liver resection both prolongs survival and offers the chance for cure for selected patients with oligometastates of the liver or hepatocellular carcinoma. ${ }^{3,13,14}$
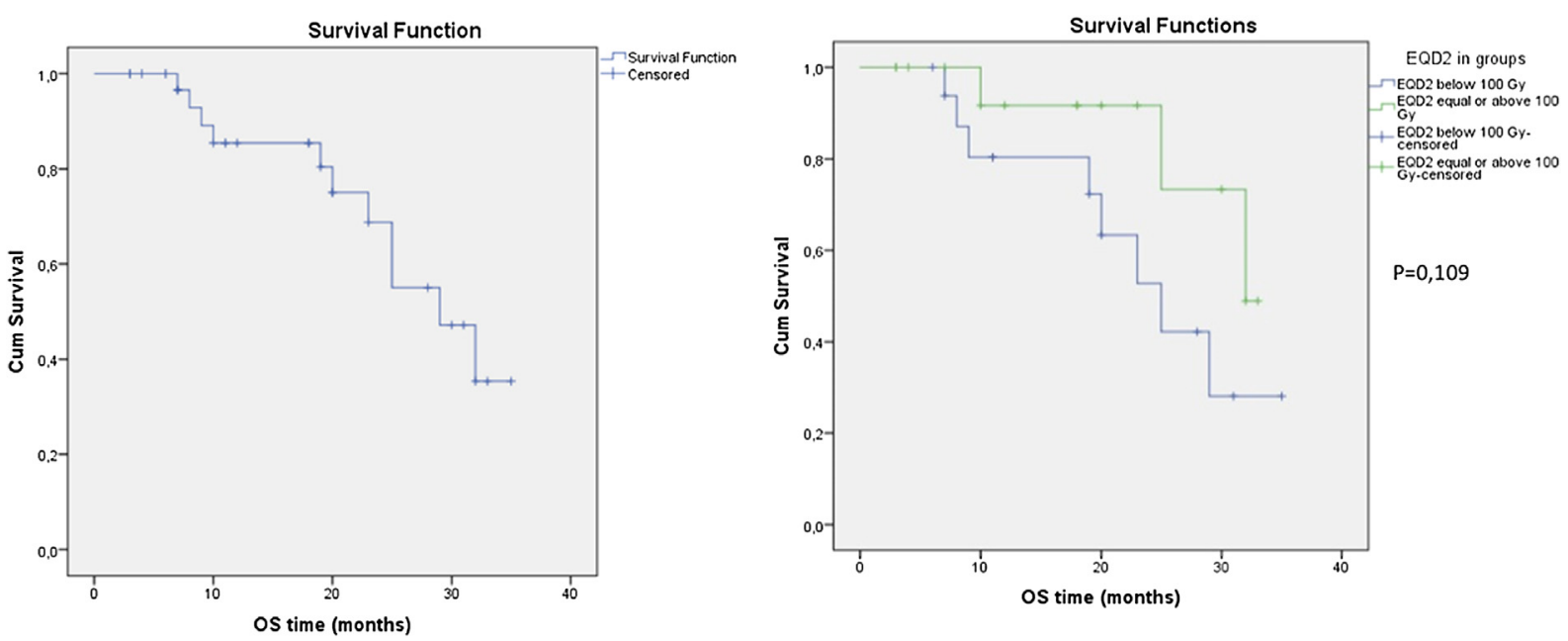

Figure 4. Kaplan-Meier estimates of overall survival (left) among patients stratified by EQD2 dose (right). 
Unfortunately, only a minority of these lesions are resectable at presentation. Risk scoring systems (e.g. Fong score) are of limited clinical utility and the definition of 'unresectable' is often based on the aggressiveness of the liver surgeon. ${ }^{4,15-17}$ Injudicious and excessive use of chemotherapy and biologics to convert liver-limited but unresectable disease can cause irreversible liver parenchymal damage that leads to increased postoperative morbidity and mortality. ${ }^{18}$ Furthermore, multiple studies have shown that the results of repeat hepatectomy for liver recurrent disease are comparable to the first resection in terms of overall survival, but often at the cost of higher perioperative mortality and morbidity.

New and innovative treatment strategies to ablate liver tumors are rapidly developing (e.g., microwave, nanoknife or irreversible electroporation, intra-arterial brachytherapy). These treatments have limitations and advantages, but all of them are associated with a minimal invasive component. Stereotactic radiotherapy of the liver has emerged as a valuable alternative primary or complementary treatment strategy for liver oligometastatic disease or primary HCC, especially when vascular proximity or multinodularity is present. ${ }^{19-22}$ The advantage of SABR is its true non-invasive aspect and the independence of tumor location or risk of biliary injury. The ability to give large doses in fractions creates the possibility of additional biological effects resulting from endothelial cell damage and/or enhanced tumor immunity. ${ }^{23}$ Until now, no large prospective studies or randomized studies have compared SABR with surgery and other treatment modalities.

In this study, we analyzed a prospective series of patients treated by SABR liver after evaluation by a universityhospital-based multidisciplinary team. The results of the analysis are challenging since our patient population was characterized by old age and frailty, with or without preexisting liver disease. This study also has some limitations since it is a retrospective investigation retrieved from a reallife university hospital clinical environment. We report a complete remission in $27 \%$ of patients but define local control as complete or partial remission. This percentage of complete remission could be an underestimation because of inaccurate radiologic response interpretation especially just after implementing this technique. The administration of ablative radiation doses can result in specific changes to both the tumor and the healthy hepatic parenchyma making the assessment of local changes after SABR often difficult. As SABR becomes more widely practiced there is a need for uniform guidelines in radiologic assessment of these treated lesions. We have to communicate with our radiologist that tumor size and shape are not the main criteria to differentiate between postradiotherapy effects and tumor recurrence. Reduction in viable tumor volume is considered as the optimal method for assessing local response to SABR. Furthermore, the CT based response after SABR can shift with longer follow-up but the duration of each radiologic stage is individually different. In future, it is mandatory to standardize and simplify our evaluation criteria. This way we can benefit of a better understanding of the effectiveness of this new treatment modality and allow better reproducibility of available imaging exams. Limited data, evaluating the role of diffusion-weighted magnetic resonance imaging (DW-MRI) in treatment response after SABR liver, show that apparent diffusion coefficient (ADC) increases early in response to therapy. ${ }^{24,25}$ Diffusion weighted imaging (DWI) is a technique that might hold promise as an early biomarker for sustained response to SABR especially for liver oligometastases in the non-cirrhotic liver. ${ }^{26}$ We encourage future multiinstitutional trials to incorporate imaging biomarkers in SABR liver protocol design with improvement and standardization of the DWI technique and measurement method. This will require improved collaborations between imaging scientists radiologists, hepatobiliary surgeons and radiation oncologists. Until now, we recommend using the modified RECIST criteria proposed by the American Association for the Study of Liver Diseases (AASLD) for assessment after SABR of the liver. This way the percentage of tumor necrosis is more important than change in tumor diameter. ${ }^{11}$ Another limitation in our study is that the small number of patients in the different subgroups (colorectal, non colorectal and hepatocellular carcinoma) made all-encompassing statements about outcome differences difficult because of the limited statistical power. Toxicity is mild but analysis is terse since this was not prospectively scored. Higher biologic radiation dose and smaller treatment volume seem to have prognostic value in improvement of local control.

Our treatment results compare favorably with other published data about SABR of the liver. ${ }^{9,27}$ Local control was excellent with no recurrence at the treated liver site. Although intuitively appealing, we note that when surgery provides good local control, the local control advantage provided by other non-invasive treatment modalities may not lead to a statistically significant survival advantage if the competing risk of distant metastases of the treated population is very high. Until now, the recommendations of the multidisciplinary tumor board have resulted in an unbalanced distribution of patients based on a number of factors that would prima facie suggest surgical resection. Our institution chose to maintain a non-invasive strategy, in that there were no fiducials implanted to guide radiotherapy. Our outcome data show that our high-precision radiotherapy margin recipe is definitely adequate.

SABR is a safe and non-invasive procedure provided that high-quality treatment planning is used and that constraints for the organs at risk are respected. However, caution must be taken when performing it on patients who have been treated with bevacizumab less than six weeks before radiotherapy. This anti-VEGFR monoclonal antibody has been associated with an increased incidence of bowel ulceration and perforation, both with and without 
radiotherapy. Blockage of vascularity in the bowels, resulting in hypoxia, necrosis and tissue breakdown, is probably the main cause of this toxicity. ${ }^{28-32}$ Despite several clinical factors like pre-existing liver dysfunction, prior therapy and portal vein thrombosis, accurate prediction of RILD remains a challenge. Adaptation of SABR that takes individual patients' sensitivity into account is the goal of future development. ${ }^{33}$ In addition, the use of hypoxic cell radiosensitizers can increase SABR's therapeutic ratio by overcoming potential hypoxic resistance. In this way, we could create the possibility of re-irradiating a liver tumor or using SABR as a salvage strategy in recurrent hepatocellular carcinoma. ${ }^{34}$ Among the most promising preclinical treatment approaches is combining SABR with immunotherapy: early data suggests that it causes synergistic and 'abscopal' effects in several tumor model systems. ${ }^{35}$

\section{Conclusion}

The management of liver metastases and primary hepatocellular carcinoma requires a multidisciplinary approach and the intention to treat on a case-by-case basis. Current data do not support planning for surgical resection with foreknowledge that residual disease will be left behind. ${ }^{36}$ Stereotactic radiotherapy of the liver has a firm role both as an adjunct to surgical resection and in the management of patients who are not surgical candidates. In our consecutive cohort of patients with liver-limited unresectable oligometastases of the liver or primary hepatocellular carcinoma, SABR provided excellent sustained local control. Combining 4D-PET/CT imaging with 3D cone beam CT-based in vivo dosimetric verification resulted in a highly tolerable, fast and accurate treatment. However, the ultimate proof of benefit will require a randomized controlled trial.

\section{Conflict of interest}

None.

\section{References}

1. Liang SX, Zhu XD, Lu HJ, et al. Hypofractionated three-dimensional conformal radiation therapy for primary liver carcinoma. Cancer 2005; 103:2181-8.

2. Poston GJ, Adam R, Alberts S, et al. Oncosurge: a strategy for improving resectability with curative intent in metastatic colorectal cancer. J Clin Oncol 2005;23:7125-34.

3. Rees M, Tekkis PP, Welsh FK, O'Rourke T, John TG. Evaluation of long-term survival after hepatic resection for metastatic colorectal cancer: a multifactorial model of 929 patients. Ann Surg 2008;247: 125-35.

4. Roberts KJ, White A, Cockbain A, et al. Performance of prognostic scores in predicting long-term outcome following resection of colorectal liver metastases. Br J Surg 2014;101:856-66.

5. Topkan E, Onal HC, Yavuz MN. Managing liver metastases with conformal radiation therapy. J Support Oncol 2008;6. 9-13, 15.
6. Wulf J, Guckenberger M, Haedinger U, et al. Stereotactic radiotherapy of primary liver cancer and hepatic metastases. Acta Oncol 2006;45: 838-47.

7. Park W, Lim DH, Paik SW, et al. Local radiotherapy for patients with unresectable hepatocellular carcinoma. Int J Radiat Oncol Biol Phys 2005;61:1143-50.

8. Seo YS, Kim JN, Keum B, et al. Radiotherapy for 65 patients with advanced unresectable hepatocellular carcinoma. World J Gastroenterol 2008;14:2394-400.

9. Seong J, Park HC, Han KH, Chon CY. Clinical results and prognostic factors in radiotherapy for unresectable hepatocellular carcinoma: a retrospective study of 158 patients. Int J Radiat Oncol Biol Phys 2003;55:329-36.

10. van Elmpt W, Nijsten S, Petit S, Mijnheer B, Lambin P, Dekker A. 3d in vivo dosimetry using megavoltage cone-beam ct and epid dosimetry. Int J Radiat Oncol Biol Phys 2009;73:1580-7.

11. Eisenhauer EA, Therasse P, Bogaerts J, et al. New response evaluation criteria in solid tumours: revised recist guideline (version 1.1). Eur J Cancer 2009;45:228-47.

12. Institute NC. Common terminology criteria for adverse events v4.0. NCI, NIH, DHHS; 2009. NIH publication \# 09-7473.

13. Chu F, Morris DL. Single centre experience of liver resection for hepatocellular carcinoma in patients outside transplant criteria. Eur $J$ Surg Oncol 2006;32:568-72.

14. Robertson DJ, Stukel TA, Gottlieb DJ, Sutherland JM, Fisher ES. Survival after hepatic resection of colorectal cancer metastases: a national experience. Cancer 2009;115:752-9.

15. Khatri VP, Petrelli NJ, Belghiti J. Extending the frontiers of surgical therapy for hepatic colorectal metastases: is there a limit? J Clin Oncol 2005;23:8490-9.

16. Konopke R, Kersting S, Distler M, et al. Prognostic factors and evaluation of a clinical score for predicting survival after resection of colorectal liver metastases. Liver Int 2009;29:89-102.

17. Zakaria S, Donohue JH, Que FG, et al. Hepatic resection for colorectal metastases: value for risk scoring systems? Ann Surg 2007; 246:183-91.

18. Robinson SM, Wilson CH, Burt AD, Manas DM, White SA. Chemotherapy-associated liver injury in patients with colorectal liver metastases: a systematic review and meta-analysis. Ann Surg Oncol 2012; 19:4287-99.

19. Kim DY, Park W, Lim DH, et al. Three-dimensional conformal radiotherapy for portal vein thrombosis of hepatocellular carcinoma. Cancer 2005;103:2419-26.

20. Goldberg SN, Hahn PF, Tanabe KK, et al. Percutaneous radiofrequency tissue ablation: does perfusion-mediated tissue cooling limit coagulation necrosis? J Vasc Interv Radiol 1998;9:101-11.

21. Lu DS, Raman SS, Limanond P, et al. Influence of large peritumoral vessels on outcome of radiofrequency ablation of liver tumors. $J$ Vasc Interv Radiol 2003;14:1267-74.

22. Machi J, Uchida S, Sumida K, et al. Ultrasound-guided radiofrequency thermal ablation of liver tumors: percutaneous, laparoscopic, and open surgical approaches. J Gastrointest Surg 2001;5:477-89.

23. Brown JM, Carlson DJ, Brenner DJ. The tumor radiobiology of srs and sbrt: are more than the 5 rs involved? Int J Radiat Oncol Biol Phys 2014;88:254-62.

24. Eccles CL, Haider EA, Haider MA, Fung S, Lockwood G, Dawson LA. Change in diffusion weighted mri during liver cancer radiotherapy: preliminary observations. Acta Oncol 2009;48:1034-43.

25. Schmid-Tannwald C, Strobl FF, Theisen D, et al. Diffusion-weighted mri before and after robotic radiosurgery (cyberknife) in primary and secondary liver malignancies: a pilot study. Technol Cancer Res Treat 2014;3. [Epub ahead of print].

26. Mungai F, Pasquinelli F, Mazzoni LN, et al. Diffusion-weighted magnetic resonance imaging in the prediction and assessment of chemotherapy outcome in liver metastases. Radiol Med 2014;119:625-33.

27. Scorsetti M, Clerici E, Comito T. Stereotactic body radiation therapy for liver metastases. J Gastrointest Oncol 2014;5:190-7. 
28. Badgwell BD, Camp ER, Feig B, et al. Management of bevacizumabassociated bowel perforation: a case series and review of the literature. Ann Oncol 2008;19:577-82.

29. Giantonio BJ, Catalano PJ, Meropol NJ, et al. Bevacizumab in combination with oxaliplatin, fluorouracil, and leucovorin (folfox4) for previously treated metastatic colorectal cancer: results from the eastern cooperative oncology group study e3200. J Clin Oncol 2007;25: $1539-44$.

30. Heinzerling JH, Huerta S. Bowel perforation from bevacizumab for the treatment of metastatic colon cancer: incidence, etiology, and management. Curr Surg 2006;63:334-7.

31. Hurwitz H, Fehrenbacher L, Novotny W, et al. Bevacizumab plus irinotecan, fluorouracil, and leucovorin for metastatic colorectal cancer. N Engl J Med 2004;350:2335-42.
32. Yang JC, Haworth L, Sherry RM, et al. A randomized trial of bevacizumab, an anti-vascular endothelial growth factor antibody, for metastatic renal cancer. N Engl J Med 2003;349:427-34.

33. Stenmark MH, Cao Y, Wang $\mathrm{H}$, et al. Estimating functional liver reserve following hepatic irradiation: adaptive normal tissue response models. Radiother Oncol 2014;111:418-23.

34. Brown JM, Diehn M, Loo Jr BW. Stereotactic ablative radiotherapy should be combined with a hypoxic cell radiosensitizer. Int J Radiat Oncol Biol Phys 2010;78:323-7.

35. Zeng J, Harris TJ, Lim M, Drake CG, Tran PT. Immune modulation and stereotactic radiation: improving local and abscopal responses. Biomed Res Int 2013;658126.

36. Lordan JT, Karanjia ND. 'Close shave' in liver resection for colorectal liver metastases. Eur J Surg Oncol 2010;36:47-51. 